\title{
Water management, rice varieties and mycorrhizal inoculation influence arsenic concentration and speciation in rice grains
}

\author{
Xin Zhang ${ }^{1} \cdot$ Songlin $\mathrm{Wu}^{1} \cdot$ Baihui Ren $^{1} \cdot$ Baodong Chen ${ }^{1}$
}

Received: 23 June 2015 / Accepted: 9 November 2015 / Published online: 19 November 2015

(C) Springer-Verlag Berlin Heidelberg 2015

\begin{abstract}
A pot experiment was carried out to investigate the effects of water management and mycorrhizal inoculation on arsenic (As) uptake by two rice varieties, the As-resistant BRRI dhan 47 (B47) and As-sensitive BRRI dhan 29 (B29). Grain As concentration of B47 plants was significantly lower than that of B29, and grain As concentration of B47 was higher under flooding conditions than that under aerobic conditions. In general, mycorrhizal inoculation (Rhizophagus irregularis) had no significant effect on grain As concentrations, but decreased the proportion of inorganic arsenic (iAs) in grains of B47. The proportion of dimethylarsinic acid (DMA) in the total grain As was dramatically higher under flooding conditions. Results demonstrate that rice variety selection and appropriate water management along with mycorrhizal inoculation could be practical countermeasures to As accumulation and toxicity in rice grains, thus reducing health risks of As exposure in rice diets.
\end{abstract}

Keywords Rice · Arsenic · Arbuscular mycorrhizal fungi · Anaerobic/aerobic cultivation $\cdot$ Metal tolerance

$\begin{array}{ll}\text { Abbreviations } & \\ \text { AMF } & \text { Arbuscular mycorrhizal fungi } \\ \text { As } & \text { Arsenic } \\ \text { As(III) } & \text { Arsenite }\end{array}$

Xin Zhang and Songlin Wu contributed equally to this work.

Baodong Chen

bdchen@rcees.ac.cn

1 State Key Laboratory of Urban and Regional Ecology, Research Center for Eco-Environmental Sciences, Chinese Academy of Sciences, Beijing 100085, China

$\begin{array}{ll}\text { As }(\text { V }) & \text { Arsenate } \\ \text { B29 } & \text { BRRI dhan 29 } \\ \text { B47 } & \text { BRRI dhan 47 } \\ \text { DMA } & \text { Dimethylarsinic acid } \\ \text { HPLC-ICP- } & \text { High performance liquid } \\ \text { MS } & \text { chromatography-inductively } \\ & \text { coupled plasma-massspectrometry } \\ \text { iAs } & \text { Inorganic arsenic } \\ \text { ICP-OES } & \text { Inductively coupled } \\ & \text { plasma-optical emission } \\ & \text { spectrometer } \\ \text { ICP-MS } & \text { Inductively coupled plasma-mass } \\ & \text { spectroscopy } \\ \text { MMA } & \text { Monomethylarsonic acid } \\ \text { R. irregularis } & \text { Rhizophagus irregularis } \\ \text { TFA } & \text { Trifluoroacetic acid }\end{array}$

Introduction

Rice (Oryza sativa L.) is the staple food for 3 billion people worldwide (Stone 2008). However, elevated concentrations of arsenic (As), a non-threshold class 1 human carcinogen, in rice grains have aroused health concern (Meharg 2004; Zhu et al. 2008b). Irrigation with As-contaminated groundwater and mining activities around rice cultivation areas has aggravated As accumulation in paddy soils (Liao et al. 2005; Williams et al. 2009). As rice is traditionally cultivated in flooded paddy soil and particularly efficient in As uptake compared with other cereal crops (Williams et al. 2007), it is highly risky to grow rice in As-impacted paddy soils, and there is an urgent need to control As accumulation in rice grains by appropriate agronomical practices.

Both inorganic As (iAs, arsenate, and arsenite) and organic As (monomethylarsonic acid (MMA) and dimethylarsinic 
acid (DMA)) are present in rice vegetative tissues and grains (Williams et al. 2005; Zhu et al. 2008a). The As speciation and their concentrations in rice are determined by many factors, such as rice variety, the uptake capacity of roots, and soil water conditions (aerobic or anaerobic) (Zheng et al. 2011). Genotypic variation in As accumulation and speciation in rice grains has been reported (Norton et al. 2009; Wu et al. 2011). Norton et al. (2009) found dramatic variations in grain As concentration among 76 rice cultivars grown in two paddy fields in Bangladesh. Wu et al. (2011) also noted that 20 rice cultivars varied in the percentage of iAs from 19 to $95 \%$ and in the percentage of DMA from 2 to $81 \%$ in a pot experiment. Speciation of As in rice grains is dominated by iAs and DMA (Meharg et al. 2009), iAs posing a greater risk to human health than DMA (Norton et al. 2009). Zavala et al. (2008) have categorized rice into DMA and inorganic As types according to the dominant As species in the rice grain, where the DMA rice type posed lower health risk than the inorganic As rice type. Syu et al. (2015) found that DMA concentrations increased with total As concentrations in grains of the DMA rice type, whereas the arsenite levels remained in a small and narrow range from 0.1 to $0.3 \mathrm{mg} \mathrm{kg}^{-1}$. Therefore, health risks may not increase through consumption of rice even when total As content in the grains increases. However, Sinha and Bhattacharyya (2015) reported that intake of Indian rice belonging to the inorganic As rice type could pose great risk to human health; urinary As concentrations of local people were found to positively correlate with those having arsenicosis skin lesions. Therefore, to select rice varieties with lower grain As concentrations and a higher proportion of DMA would be a promising way to mitigate health risks associated with rice diets.

Besides rice variety, the physiological traits of rice root systems are another factor that influences As uptake from soil. Arbuscular mycorrhizal fungi (AMF) are ubiquitous symbionts for the majority of higher plants in the terrestrial ecosystems (Smith and Read 2008). It has been well documented that AMF may play an important role in protecting host plants against As contamination (Chen et al. 2007; Liu et al. 2005). AMF essentially improve plant phosphorus (P) nutrition and growth, which could result in a higher $\mathrm{P} / \mathrm{As}$ ratio and a dilution effect on As in mycorrhizal plants (Ultra et al. 2007; Xia et al. 2007; Dong et al. 2008; Caporale et al. 2014; Spagnoletti and Lavado 2015). Smith et al. (2010), Christophersen et al. (2012), and He and Lilleskov (2014) compared the root and mycorrhizal $\mathrm{Pi} /$ arsenate $(\mathrm{As}(\mathrm{V}))$ uptake pathways and confirmed the important role of AMF in plant resistance to As contamination. Moreover, As-tolerant fungi may provide additional benefits to host plants over non-tolerant fungi (Orlowska et al. 2012). As-tolerant mycorrhizal fungi have also been reported to enhance arsenite (As(III)) exudation and reduce $\mathrm{As}(\mathrm{V})$ uptake in an As-contaminated environment and thus confer enhanced As tolerance on host plants
(Gonzalez-Chavez et al. 2002). The capacity of AMF to enhance As tolerance of rice plants in paddy soil has also been addressed recently ( $\mathrm{Li}$ et al. 2011, 2013). Li et al. (2011) reported that lowland rice inoculated with Rhizophagus irregularis and upland rice inoculated with Glomus geosporum exhibited higher grain yield, higher grain $\mathrm{P}$ content, and higher molar ratio of grain $\mathrm{P} / \mathrm{As}$. Moreover, R. irregularis led to elevated $\mathrm{As}(\mathrm{III}) / \mathrm{As}(\mathrm{V})$ ratios in roots (Li et al. 2013). Furthermore, Chan et al. (2015) reported reduced $\mathrm{As}(\mathrm{III})$ and $\mathrm{As}(\mathrm{V})$ uptake by paddy rice Zhonghan 221 in mycorrhizal plants compared to non-mycorrhizal controls. Although mycorrhiza-mediated As accumulation and speciation have been reported in rice tissues, the potential influence of AMF on As speciation in rice grains has so far not been investigated. Since rice is a daily diet for 3 billion people worldwide (Stone 2008), it is more important to investigate As concentration and speciation in rice grains than in rice vegetative tissues.

Water management also has remarkable influences on As speciation and accumulation in rice. Flooding conditions in paddy soil lead to mobilization of As(III) into the soil solution and therefore an increase in As uptake. While DMA has been found to account for the majority of the total As in rice grain in flooded paddy soil (Xu et al. 2008), aerobic cultivation of rice may reduce As accumulation and largely save water, which is strongly recommended for rice production ( $\mathrm{Li}$ et al. 2011).

In the present study, two rice varieties were selected with different As tolerance, the As-resistant BRRI dhan 47 (Rahman et al. 2012) and As-sensitive BRRI dhan 29 (Talukder et al. 2012), to investigate the effects of water management and AMF inoculation on As accumulation in rice grains. The main objectives of the study were to (1) investigate the interactive influences of water management and AMF inoculation on grain As concentration and speciation in the two rice varieties and (2) identify the best combination of rice variety, water management, and AMF inoculation to produce rice grain with lower As content and a higher proportion of organic As.

\section{Materials and methods}

\section{Host plants and arbuscular mycorrhizal fungi}

Seeds of BRRI dhan47 (B47) and BRRI dhan29 (B29) were obtained from the Bangladesh Rice Research Institute (BRRI). They were surface-sterilized in a $10 \%(v / v)$ solution of hydrogen peroxide for $10 \mathrm{~min}$ then immersed in deionized water for $10 \mathrm{~h}$ and pre-germinated on moist filter paper for about $48 \mathrm{~h}$ at $27{ }^{\circ} \mathrm{C}$ until appearance of radicles. The geminated seeds were selected for uniformity before sowing. The AMF R. irregularis Błaszk., Wubet, Renker, and Buscot (recently renamed from Glomus intraradices Schenck \& Smith 
by Schüßler and Walker 2010), isolate BGC AH01, was provided by the Institute of Plant Nutrition and Resources, Beijing Academy of Agriculture and Forestry. The fungal inoculum was a mixture of spores, mycelium, sandy soil, and root fragments containing approximately 1000 spores per $100 \mathrm{~g}$.

\section{Cultivation media}

The experimental soil was collected from paddy fields in the suburb of Beijing (N40 06 46", E116 $\left.16^{\prime} 48^{\prime \prime}\right)$, Northern China. The soil was passed through a 2-mm sieve, sterilized by irradiation ( $20 \mathrm{kGy}, 10 \mathrm{MeV}$ electron beam), and amended with basal nutrients without $\mathrm{P}$ as recommended by Pearson and Jakobsen (1993). The soil had a $\mathrm{pH}$ value of 7.9 (1:2.5 soil to water), $5.25 \%$ organic matter, $13.0 \mathrm{mg} \mathrm{kg}^{-1}$ extractable $\mathrm{P}$ (extracted by $0.5 \mathrm{~mol} \mathrm{~L}^{-1} \mathrm{NaHCO}_{3}$ following the methods described by Olsen et al. (1954)), and $4.54 \mathrm{mg} \mathrm{kg}^{-1}$ extractable As (extracted by $0.5 \mathrm{~mol} \mathrm{~L}^{-1} \mathrm{NaHCO}_{3}$ ). The soil contained $93.53 \mathrm{mg} \mathrm{As} \mathrm{kg}^{-1}, 14.03 \mathrm{mg} \mathrm{Cu} \mathrm{g}^{-1}, 566.18 \mathrm{mg}$ $\mathrm{Mg} \mathrm{kg}^{-1}, 358.22 \mathrm{mg} \mathrm{Mn} \mathrm{kg}^{-1}$, and $103.18 \mathrm{mg} \mathrm{Zn} \mathrm{kg}^{-1}$ in total metal contents that were measured by inductively coupled plasma-optical emission spectroscopy (ICP-OES, Prodigy, Teledyne Leeman Labs) following $\mathrm{HNO}_{3}-\mathrm{HF}$ digestion.

\section{Experimental procedure}

To establish mycorrhiza between rice plants and $R$. irregularis, $60 \mathrm{~g}$ of the fungal inoculum was mixed into $2 \mathrm{~kg}$ sand then filled into round plastic pots $(\varnothing 180 \mathrm{~cm} \times 160 \mathrm{~cm})$, and six pregerminated seeds of each rice variety were sown into each pot. Non-mycorrhizal (NM) treatments received an equivalent amount of autoclaved inoculum together with a filtrate of the fungal inoculum to provide a similar microflora except for the mycorrhizal fungus. After addition of the microbial filtrate, the soil was left for 2 weeks to allow establishment of soil microbial communities. Seedlings were thinned to two per pot after emergence and fertilized with half-strength Kimura nutrient solution (Li et al. 2009a) once per week. Eight weeks later, when the plant roots were well colonized, seedlings were transplanted into another pot with the same size but contained $2 \mathrm{~kg} \mathrm{1:1(w/w)} \mathrm{mixture} \mathrm{of} \mathrm{paddy} \mathrm{soil} \mathrm{and} \mathrm{sand} \mathrm{amended} \mathrm{with}$ $10 \mathrm{mg} / \mathrm{kg} \mathrm{As}(\mathrm{V})$. Two weeks later, half of the pots were irrigated with distilled water to maintain a water layer above the soil surface and flooding conditions were maintained throughout the growth period. For the other half of the pots, soil moisture content was maintained at $55 \%$ water holding capacity by regular weighing to serve as aerobic cultivation of rice plants. As a result, there were two mycorrhizal (AMF and $\mathrm{NM}$ ) and two water managements (aerobic and flooding) on two rice varieties (B47 and B29), resulting in a total of 8 treatments. Each treatment had four replicates giving a total of 32 pots in a randomized block design. The experiment was conducted in a controlled environment growth chamber with
$16 \mathrm{~h} / 25{ }^{\circ} \mathrm{C}$ day and $8 \mathrm{~h} / 18{ }^{\circ} \mathrm{C}$ night at a light intensity of $700 \mu \mathrm{mol} \mathrm{m} \mathrm{s}^{-2}$ provided by supplementary illumination.

\section{Harvest and chemical analysis}

Rice plants were grown for 9 months until maturity. Plant shoots and roots were harvested separately. Root samples were first carefully washed with tap water to remove adhering soil particles and rinsed in ice-cold phosphate solution containing $1.0 \mathrm{mM} \mathrm{K}_{2} \mathrm{HPO}_{4}, 5.0 \mathrm{mM}$ MES, and $0.5 \mathrm{mM}$ $\mathrm{Ca}\left(\mathrm{NO}_{3}\right)_{2}$ for $10 \mathrm{~min}$ to remove As in the apoplast of the roots (Abedin et al. 2002). Roots and shoots were then thoroughly washed with de-ionized water, blotted dry, and weighed. Subsamples of fresh roots were collected for the determination of AMF colonization rate. Remaining samples were frozen in liquid nitrogen, and dry weights were recorded after freezedrying for $72 \mathrm{~h}$.

Sub-samples of fresh roots were cleared in $10 \% \mathrm{KOH}$ and stained with Trypan blue by a modification procedure of Phillips and Hayman (Phillips and Hayman 1970), omitting phenol from solutions and $\mathrm{HCl}$ from the rinse. Percentage root colonization was determined by the grid-intersect method (Giovannetti and Mosse 1980).

Approximately $0.2 \mathrm{~g}$ freeze-dried samples were weighed and digested by $10 \mathrm{ml} \mathrm{HNO}_{3}$ using a microwave accelerated reaction system (Mars 5, CEM Co., Ltd, USA). The dissolved samples were analyzed for P by ICP-OES (Prodigy, Teledyne Leeman Labs) and for As by ICP-mass spectroscopy (ICPMS, Agilent7500, Agilent Technology, USA).

For As analyses, freeze-dried root and flag leaf samples were extracted with $10 \mathrm{ml}$ of $1 \%$ nitric acid in the microwave accelerated reaction system. Grain was ground into fine powder, and aliquots of grain samples $(0.5 \mathrm{~g})$ were extracted with $2 \mathrm{~mL} 2 \mathrm{M}$ trifluoroacetic acid (TFA) according to Williams et al. (2005). The certified reference material GBW 10010 Chinese rice flour was used to validate the analytical procedure. Spikes of both $\mathrm{As}(\mathrm{III})$ and $\mathrm{As}(\mathrm{V})(0.5 \mathrm{ml}$ of $1000 \mu \mathrm{g}$ $\mathrm{As} \mathrm{ml}^{-1}$ ) and blanks were run with each extraction batch. The extracted solutions were filtered and passed through a $0.45-\mu \mathrm{m}$ nylon filter. Samples were kept on ice in the dark and analyzed soon after extraction in order to minimize potential transformation of As species. Analysis of As species in freeze-dried shoots and roots was determined by high performance liquid chromatography-ICP-MS (HPLC-ICP-MS, Agilent 7500, Agilent Technology, USA). Chromatographic columns consisted of a Hamilton precolumn (11.2 mm, 12$20 \mathrm{~mm}$ ) and a Hamilton PRP-X100 10- $\mathrm{mm}$ anion exchange column $(240 \times 4.1 \mathrm{~mm})$. The mobile phase consisted of $10 \mathrm{mM} \mathrm{NH}_{4} \mathrm{H}_{2} \mathrm{PO}_{4}$ and $\mathrm{NH}_{4} \mathrm{NO}_{3}$, adjusted to $\mathrm{pH} 6.2$ using ammonia. Arsenic speciation in the extracts was verified by the coincidence of retention times with those of the standards including $\mathrm{As}(\mathrm{III}), \mathrm{As}(\mathrm{V}), \mathrm{DMA}$, and MMA and quantified by external calibration curves with peak areas. 


\section{Data analysis}

Data were subjected to three-way ANOVA to compare rice varieties, water management, and mycorrhizal status using windows-based SPSS 16.0 statistical package (SPSS Inc., USA). Based on ANOVA output, the differences between means were examined using Duncan's multiple range Test at 0.05 probability level. When there were no significant interactions between factors, data were subjected to a $t$ test to identify significant differences between treatments.

\section{Results}

\section{Mycorrhizal colonization}

No root colonization was detected in uninoculated rice plants, while roots of $R$. irregularis-inoculated plants were extensively colonized under both aerobic and flooding conditions, with mean colonization levels ranging from 24 to $73 \%$ (Table 1 ). In general, root colonization levels of both rice varieties under aerobic conditions were significantly higher than those under flooding conditions $(P<0.05)$, and root colonization of B47 was significantly higher than that of B29 $(P<0.05)$.

\section{Plant biomass}

Neither rice variety nor AMF inoculation showed a significant effect on grain yield, whereas aerobic water management increased the grain yield of the uninoculated B29 variety $(P<0.05)$ (Fig. 1). For straw biomass, water management and $R$. irregularis inoculation showed no significant effect on $\mathrm{B} 47$, but $R$. irregularis significantly decreased the straw biomass of B29 $(P<0.01)$ and aerobic cultivation increased the straw biomass of mycorrhizal B29 $(P<0.01)$. Mycorrhiza increased the root biomass under flooding conditions for B47 $(P<0.05)$, while for B29, mycorrhiza decreased the root biomass irrespective of water regimes $(P<0.05)$.

\section{Phosphorus concentration}

The interaction between mycorrhizal inoculation and plant varieties had a significant effect on rice grain $\mathrm{P}$ concentration $(P<0.05$, Fig. 2). Under flooding conditions, grain $\mathrm{P}$ concentration of B47 was significantly higher $(P<0.05)$ than that of B29, irrespective of the inoculation treatment, while $R$. irregularis significantly increased the grain $\mathrm{P}$ concentration of B47 under aerobic conditions. In contrast, there were no significant differences in the straw and root $\mathrm{P}$ concentrations between treatments.
Table 1 Mycorrhizal colonization levels of two rice varieties (BRRI dhan 47 and BRRI dhan 29) inoculated with Rhizophagus irregularis or noninoculated, under aerobic or flooded conditions

\begin{tabular}{|c|c|c|c|}
\hline Inoculation treatment & $\begin{array}{l}\text { Plant } \\
\text { variety }\end{array}$ & $\begin{array}{l}\text { Water } \\
\text { mangement }\end{array}$ & Root colonization $(\%)$ \\
\hline \multirow[t]{4}{*}{ Non-inoculated } & \multirow[t]{2}{*}{ B47 } & Aerobic & $0^{\mathrm{a}}$ \\
\hline & & Flooded & $0^{\mathrm{a}}$ \\
\hline & \multirow[t]{2}{*}{ B29 } & Aerobic & $0^{\mathrm{x}}$ \\
\hline & & Flooded & $0^{\mathrm{x}}$ \\
\hline \multirow[t]{4}{*}{ Inoculated } & \multirow[t]{2}{*}{ B47 } & Aerobic & $73^{\mathrm{b}}$ \\
\hline & & Flooded & $47^{\mathrm{c}}$ \\
\hline & \multirow[t]{2}{*}{ B29 } & Aerobic & $63^{\mathrm{y}}$ \\
\hline & & Flooded & $24^{z}$ \\
\hline \multicolumn{4}{|l|}{$\begin{array}{l}\text { Significance of: } \\
\text { Inoculation (I) }\end{array}$} \\
\hline Inoculation (I) & & & * \\
\hline Plant (P) & & & $* *$ \\
\hline Water (W) & & & * \\
\hline $\mathrm{I} \times \mathrm{P}$ & & & $* *$ \\
\hline $\mathrm{P} \times \mathrm{W}$ & & & NS \\
\hline $\mathrm{I} \times \mathrm{W}$ & & & * \\
\hline $\mathrm{I} \times \mathrm{P} \times \mathrm{W}$ & & & NS \\
\hline
\end{tabular}

Data presented are means of four replicates. Different lower case letters (a, b, c or x, y, z) following the means indicate significant differences $(P<0.05)$ between water and inoculation treatments of each rice cultivar by Duncan's multiple range test

$N S$ not significant

${ }^{*} P<0.001 ; * * P<0.01$ (by ANOVA) 

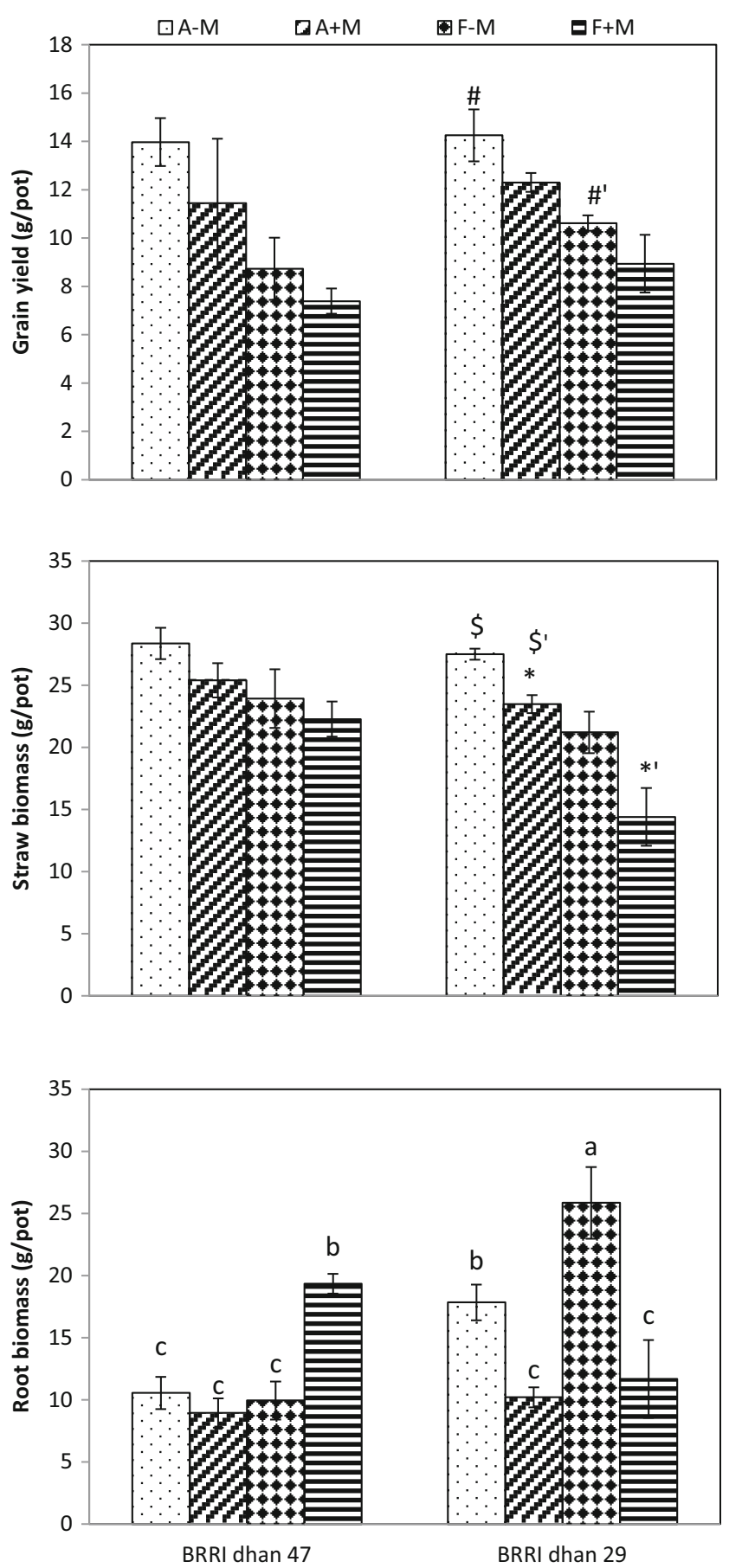

\section{Arsenic concentration}

The grain As concentration of B47 was significantly lower than that of B29 $(P<0.05)$. Aerobic water management decreased the grain As concentration of B47, whereas $R$. irregularis inoculation showed no significant effect on the grain As concentration of either rice variety (Fig. 3). Similarly, the straw As concentration of B47 was also lower than that of B29 $(P<0.05)$. Aerobic water management decreased straw As concentration in mycorrhizal $\mathrm{B} 47$, while $R$. irregularis
Fig. 1 Grain yield, straw, and root biomass of As-resistant BRRI dhan 47 and As-sensitive BRRI dhan 29 inoculated with/without Rhizophagus irregularis grown under aerobic and flooded conditions. $\mathrm{A}-\mathrm{M}$, aerobic cultivation without inoculation; $\mathrm{A}+\mathrm{M}$, aerobic cultivation with R. irregularis inoculation; $\mathrm{F}-\mathrm{M}$, flooding without inoculation; $\mathrm{F}+\mathrm{M}$, flooding with $R$. irregularis inoculation. By ANOVA, grain yield did not differ between the two rice varieties, but was significantly affected by water management $(P<0.001)$ and $R$. irregularis inoculation $(P<0.05)$. Effects of rice variety $(P<0.01), R$. irregularis inoculation $(P<0.01)$, and water management $(P<0.001)$ were significant for straw biomass. The interaction between the three experimental factors was significant $(P<0.01)$ for root biomass. For grain yield and straw biomass, paired symbols (\# and \#', \$ and \$', * and *') indicate significant differences $(P<0.05)$ between corresponding treatments by $t$ test. For root biomass, different lower case letters indicate significant differences $(P<0.05)$ between treatments by Duncan's multiple range test

inoculation decreased the straw As concentration of B29 under aerobic conditions. Aerobic water management significantly decreased the root As concentration of B47, and R. irregularis inoculation had no significant effect on the root As concentrations except for significantly increasing root As concentration of B29 under flooding conditions $(P<0.05)$.

\section{Arsenic speciation}

No DMA was detected in the roots of either rice variety, irrespective of the experimental treatments (Fig. 4). As(III) accounted for $9.3 \%$ of the root As uptake in the uninoculated B29 and $47.9 \%$ in the uninoculated B47 under flooded conditions.

In flag leaves, the percentage of As(III) in the total As uptake of flag leaf was significantly higher than that in the root ranging from 72.6 to $95.1 \%$. Furthermore, DMA was detected in flag leaves except for uninoculated B47 and R. irregularis-inoculated B29 plants under aerobic conditions, although DMA only accounted for a minor proportion of the total As uptake. Under flooded conditions, the DMA fraction in the flag leaf was significantly higher than that under aerobic conditions $(P<0.05)$, and $R$. irregularis-inoculated B47 plants under flooded conditions produced the highest amount of DMA among all the treatments $(P<0.05)$.

No $\operatorname{As}(\mathrm{V})$ was detected in the grains of either rice variety. As(III) and DMA were the only As species in the rice grains, except that only As(III) was detected in the grains of uninoculated B47 plants under aerobic conditions. Under flooded conditions, the proportion of DMA in rice grains was significantly higher compared with that under aerobic conditions $(P<0.05)$, irrespective of inoculation treatments. Under aerobic conditions, DMA only accounted for $0-5.96 \%$ of total As in rice grain (Fig. 5). In contrast, a high percentage of DMA (31.4-61.7\%) was observed for both rice varieties under flooded conditions. Mycorrhizal B47 plants contained proportionally more DMA in the grain than did the corresponding uninoculated plants $(P<0.05)$, whereas there was no significant difference in the percentage of DMA between grains of $R$. irregularis-inoculated and uninoculated $\mathrm{B} 29$ plants. The 

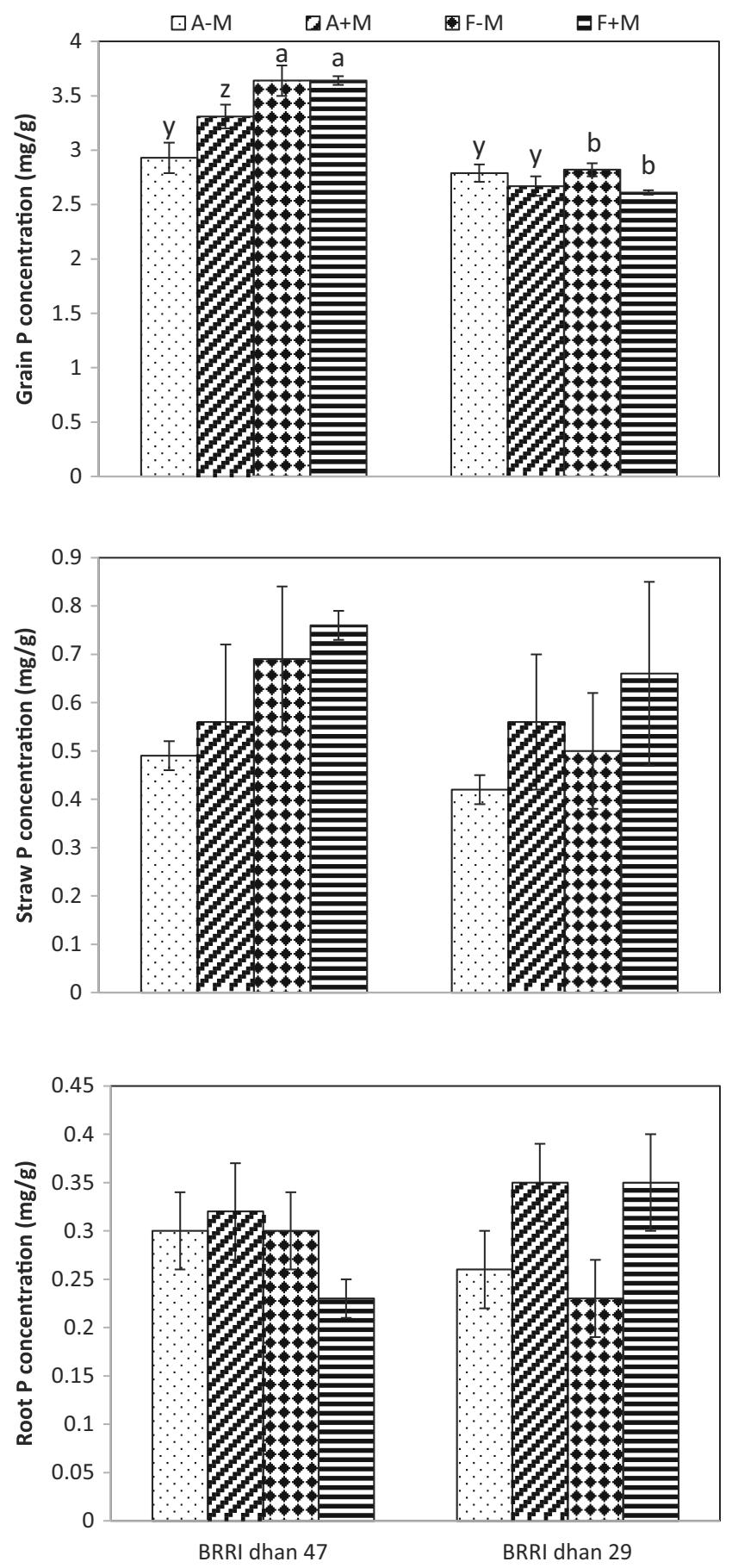

grain of $R$. irregularis-inoculated B47 under flooded conditions contained $0.12 \mathrm{mg} / \mathrm{kg}$ DMA (61.7\% in total As uptake), which was the highest level recorded among all the treatments $(P<0.05)$.

\section{Discussion}

The present study shows that As concentration and speciation in rice grains can be markedly influenced by the variety, water
Fig. 2 Grain, straw, and root $\mathrm{P}$ concentrations of As-resistant BRRI dhan 47 and As-sensitive BRRI dhan 29 inoculated with/without $R$. irregularis grown under aerobic and flooded conditions. $\mathrm{A}-\mathrm{M}$, aerobic cultivation without inoculation; $\mathrm{A}+\mathrm{M}$, aerobic cultivation with $R$. irregularis inoculation; $\mathrm{F}-\mathrm{M}$, flooding without inoculation; $\mathrm{F}+\mathrm{M}$, flooding with $R$. irregularis inoculation. By ANOVA, the interaction between $R$. irregularis inoculation and rice varieties was significant for the grain $\mathrm{P}$ concentrations $(P<0.05)$. The interaction between rice varieties and water management $(P<0.01)$ was also significant for the grain $\mathrm{P}$ concentrations. For grain $\mathrm{P}$ concentration, different lower case letters (" $\mathrm{a}, \mathrm{b}$ " or " $\mathrm{z}, \mathrm{y}$ ") indicate significant differences $(P<0.05)$ between treatments under the same water management by Duncan's multiple range test. There were no significant differences in straw and root $\mathrm{P}$ concentrations among all experimental treatments

management, and mycorrhizal status of the rice plants. In general, the grain As concentration of the B47 variety is significantly lower than that of $\mathrm{B} 29$. The B47 rice variety is regarded as As-resistant compared to other non-resistant varieties (Rahman et al. 2012), while Talukder et al. (2012) pointed out that the B29 variety is more sensitive to As and easily takes up more As than do other rice varieties, which is in accordance with the present observations. Under flooding conditions, As concentrations in roots, straw, and grains of B47 rice was much higher than those under aerobic conditions. Flooding leads to a rapid and marked mobilization of As into the soil solution and thus enhanced As uptake by plants. In contrast, growing B47 plants aerobically dramatically decreased As accumulation in the grains. Several studies have shown that As transfer from soil to grain could be reduced when rice is grown under aerobic conditions (Arao et al. 2009; Xu et al. 2008). Therefore, aerobic cultivation of B47 offers obvious advantages in term of product safety and water saving.

Under the present experimental conditions, mycorrhiza showed no significant effect on the As concentration in rice grains, irrespective of the rice variety. Li et al. (2013) reported that different rice cultivar/AMF combinations could have very different effects on grain As concentrations. These authors found that the variety Guangyinzhan inoculated with $R$. irregularis and the variety Handao 502 inoculated with G. geosporum exhibited stronger As tolerance, whereas Guangyinzhan inoculated with G. geosporum and Handao 502 inoculated with $R$. irregularis led to higher grain As concentrations. Thus, there is obvious functional diversity in the mycorrhizal symbiosis in terms of As uptake and tolerance.

Apart from decreasing the As concentration of grains, another effective way to reduce the human risks of As exposure in the rice diet is to increase the proportion of DMA in the total As in rice grains, considering that the toxicity of DMA is much lower than that of iAs (Cullen and Reimer 1989). A key finding from this study was that, for mycorrhizal B47 plants cultivated under flooded conditions, the major As species in grains was DMA, accounting for $61.7 \%$ of the total As. However, market-based surveys have shown that rice 

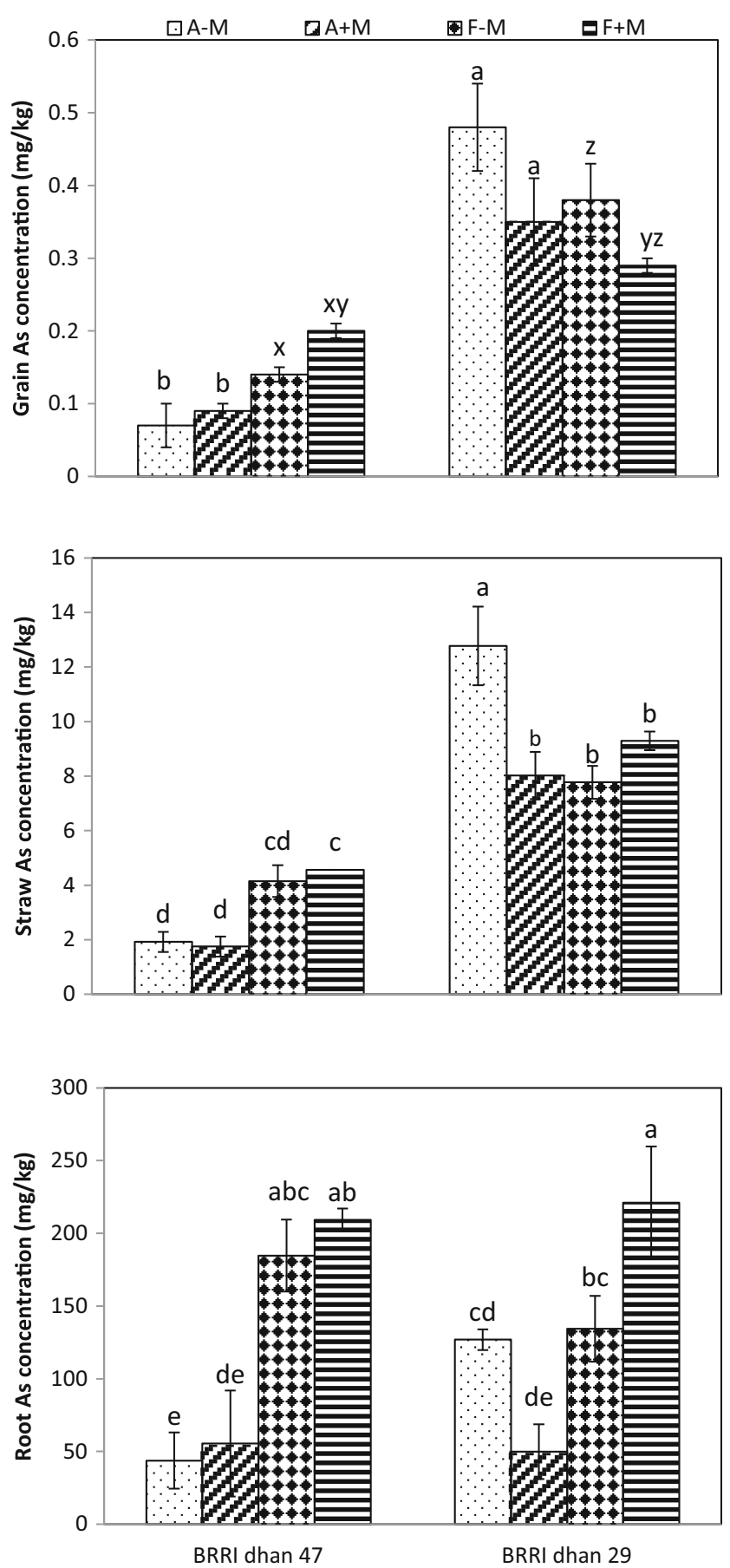

produced in Bangladesh and China contains only small percentages of DMA ( 20\%) (Williams et al. 2005; Zhu et al. 2008a) whereas the percentage of DMA in B47 grains, as influenced by $R$. irregularis inoculation and water management, could be threefold higher than that in the market survey. In the case of uninoculated B47 plants under flooding condition, the percentage of DMA in the grain decreased to $35.7 \%$, followed by mycorrhizal B47 plants under aerobic conditions $(5.11 \%)$. Furthermore, no DMA was detected in grains under aerobic condition and without AMF colonization.
Fig. 3 Grain, straw, and root total As concentraion of As-resistant BRRI dhan 47 and As-sensitive BRRI dhan 29 inoculated with/without $R$. irregularis grown under aerobic and flooded conditions. $\mathrm{A}-\mathrm{M}$, aerobic cultivation without inoculation; $\mathrm{A}+\mathrm{M}$, aerobic cultivation with $R$. irregularis inoculation; $\mathrm{F}-\mathrm{M}$, flooding without inoculation; $\mathrm{F}+\mathrm{M}$, flooding with $R$. irregularis inoculation. By ANOVA, the interactions between $R$. irregularis inoculation and rice varieties and between water management and rice varieties were significant for grain As concentrations $(P<0.05)$. The interaction between $R$. irregularis inoculation, water management, and rice varieties was significant for both straw and root As concentrations $(P<0.05)$. For grain As concentration, different lower case letters (" $\mathrm{a}, \mathrm{b}$ " or " $\mathrm{z}, \mathrm{y}, \mathrm{x}$ ") indicate significant differences $(P<0.05)$ between treatments under the same water management by Duncan's multiple range test. For straw and root As concentrations, different lower case letters above the error bars indicate significant differences $(P<0.05)$ between treatments by Duncan's multiple range test

Consequently, for this Bangladesh rice variety, flooded water management and mycorrhizal inoculation could essentially increase DMA proportion in the rice grain. A comparable effect of water management on the proportion of DMA in grains was also found for the B29 variety. Similar results have been reported by Xu et al. (2008) and Li et al. (2009b). The major reason could be that more As(III) is mobilized into the soil solution under anaerobic conditions, resulting in increased substrate availability for methylation (Zhao et al. 2013). It should be noted that although the proportion of DMA in the grains of $R$. irregularis-inoculated B47 plants under flooding conditions was relatively high $(61.7 \%)$, the total grain As concentration was also much higher than that under aerobic conditions. Thus, flooding cultivation of mycorrhizal B47 rice is not a safe practice to mitigate As accumulation in the grains. In contrast, the grain As concentration of aerobically cultivated B47 plants was much lower than that under flooding conditions, and the proportion of DMA in grains of aerobic B47 increased to $5.11 \%$ when inoculated with $R$. irregularis compared to non-inoculated controls. Therefore, aerobic cultivation of the B47 rice variety inoculated with $R$. irregularis showed overall advantages in safety guarantee of rice production in terms of lower concentration of iAs in grains.

Formation of the mycorrhizal symbiosis in B47 plants increased the potential of methylating iAs into DMA, as inoculated plants contained proportionally more DMA than did the corresponding uninoculated plants, irrespective of water management. Zhang et al. (2015) investigated the As speciation in a wild-type and a non-mycorrhizal mutant (TR25:3-1) of Medicago truncatula grown in As-contaminated soil and also found that DMA was only detected in shoots of mycorrhizal plants. It has been shown recently that methylated As speciation, such as into DMA, in rice is derived from microbial methylation in the medium and not by the plant itself (Lomax et al. 2012). Methylation of As has been well demonstrated in a wide range of bacteria, fungi, and algae (Fitz and Wenzel 2002). Thus, in the present study, the DMA detected in the rice 

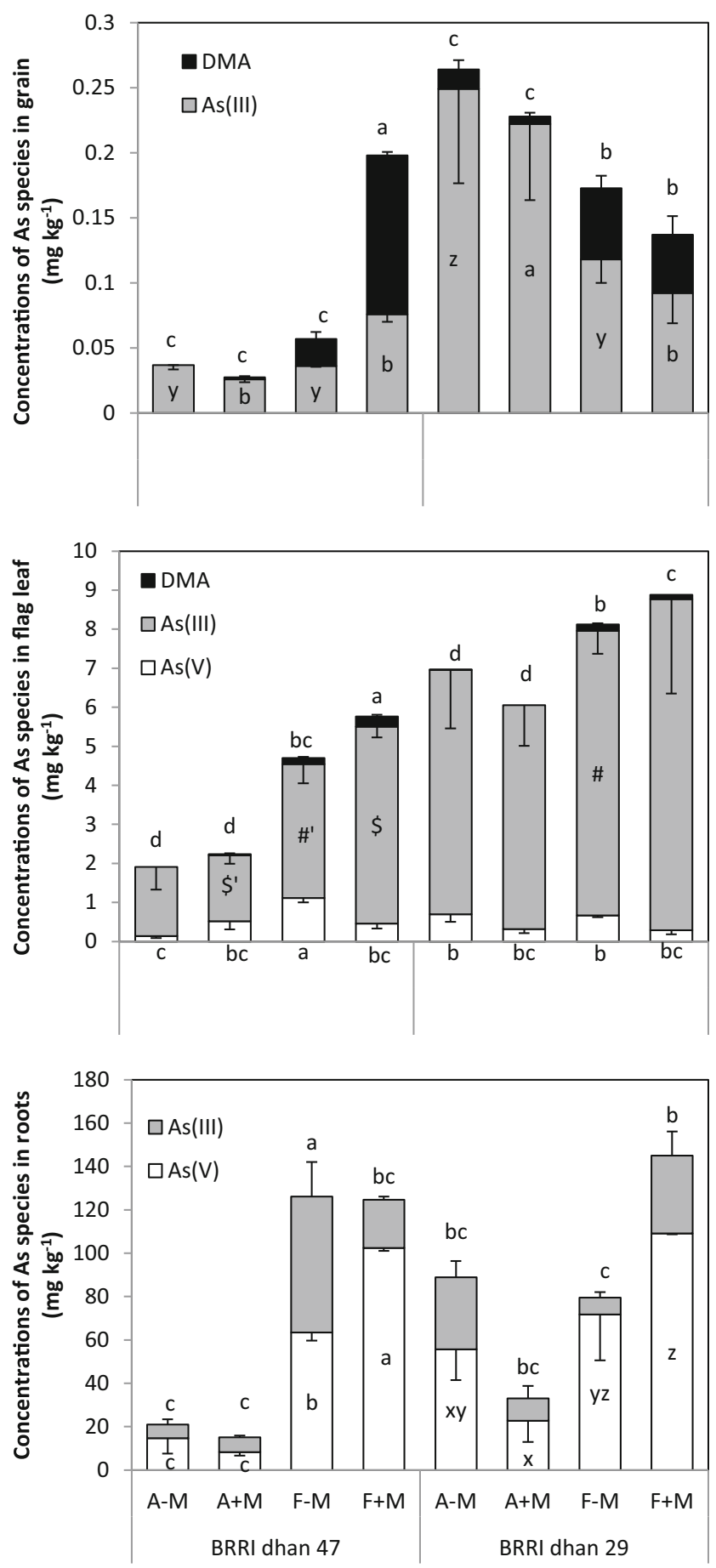

grains could have been produced by microorganisms in the growth medium and absorbed by the rice roots then quickly transported to the aboveground plant parts. Although the growth medium used in the present study was sterilized, mycorrhiza formation could have stimulated associated microorganisms (Smith and Read 2008), and the experiment was carried out in open air where other microbes could potentially be reintroduced. The abundance or activities of anaerobic microorganisms for As methylation in soil are likely to be
Fig. 4 Arsenic speciation in grain, flag leaf, and root of As-resistant BRRI dhan 47 and As-sensitive BRRI dhan 29 inoculated with/without $R$. irregularis under aerobic and flooded conditions. $\mathrm{A}-\mathrm{M}$, aerobic cultivation without inoculation; $\mathrm{A}+\mathrm{M}$, aerobic cultivation with R. irregularis inoculation; $\mathrm{F}-\mathrm{M}$, flooding without inoculation; $\mathrm{F}+\mathrm{M}$, flooding with $R$. irregularis inoculation. By ANOVA, the interaction between water management and rice varieties was significant for grain As(III) concentration $(P<0.01)$. The interaction between inoculation, water management, and rice varieties was highly significant for grain DMA concentration $(P<0.001)$ and significant for flag leaf DMA and As $(\mathrm{V})$ concentrations $(P<0.05)$. Effect of water management was significant $(P<0.05)$, and rice variety was highly significant $(P<0.001)$ for flag leaf As(III) concentration. The interaction between $R$. irregularis inoculation and water management showed a significant effect on root As $(\mathrm{V})$ concentration $(P<0.01)$, and the interaction of all three experimental factors was significant for root As(III) concentrations $(P<0.01)$. For DMA in grains and flag leaves, $\mathrm{As}(\mathrm{V})$ in flag leaves, and $\mathrm{As}(\mathrm{III})$ in roots, different lower case letters indicate significant differences $(P<0.05)$ between treatments by Duncan's multiple range test. For grain As(III), different lower case letters (" $a, b$ " or " $\mathrm{z}, \mathrm{y}$ ") indicate significant differences $(P<0.05)$ between treatments within the same inoculation treatment by Duncan's multiple range test. For root $\mathrm{As}(\mathrm{V})$, different lower case letters (" $\mathrm{a}, \mathrm{b}, \mathrm{c}$ " or " $\mathrm{z}, \mathrm{y}, \mathrm{x}$ ") indicate significant differences $(P<0.05)$ between treatments within the same rice cultivar by Duncan's multiple range test. For flag leaf As(III), paired symbols (\# and \#', \$ and $\$$ ') indicate significant difference $(P<0.05)$ between corresponding treatments by $t$ test

stimulated especially under flooding conditions (Somenahally et al. 2011a, 2011b; Zhao et al. 2013), which could have contributed to the dramatically higher proportion of DMA in the grain under flooding conditions compared with that under aerobic conditions.

While $R$. irregularis inoculation potentially contributed to iAs methylation into DMA in the grain of B47 rice, the AMF did not seem to be involved in As methylation for the B29 variety. The possible reason for this difference could be the different AMF-plant combinations that may have different capabilities in nutrient uptake, carbon transfer, and tolerance to heavy metals (Burleigh et al. 2002; Smith et al. 2004). In the present study, the mycorrhizal colonization level of B47 plants is significantly higher than that of B29 suggesting that when associated with $\mathrm{B} 47, R$. irregularis might be superior in enhancing nutrient uptake, improving As tolerance, and thus indirectly resulting in enhanced methylation ability. Therefore, association with the AMF may contribute to the methylation of iAs into less toxic DMA, but such a process is affected by the host plant and environmental factors like water management. Further research is still necessary to provide direct evidence for the involvement of AMF in As methylation.

In the present study, the proportion of DMA in rice flag leaves followed similar trends as that in grains. R. irregularisinoculated B47 plants under flooded conditions contained the highest proportion of DMA in the flag leaf. It is possible that DMA could be efficiently translocated from flag leaves to rice grains (Carey et al. 2011), resulting in a similar distribution pattern of DMA in these two plant parts. Moreover, DMA was not detected in the rice roots, while the proportion of DMA in 

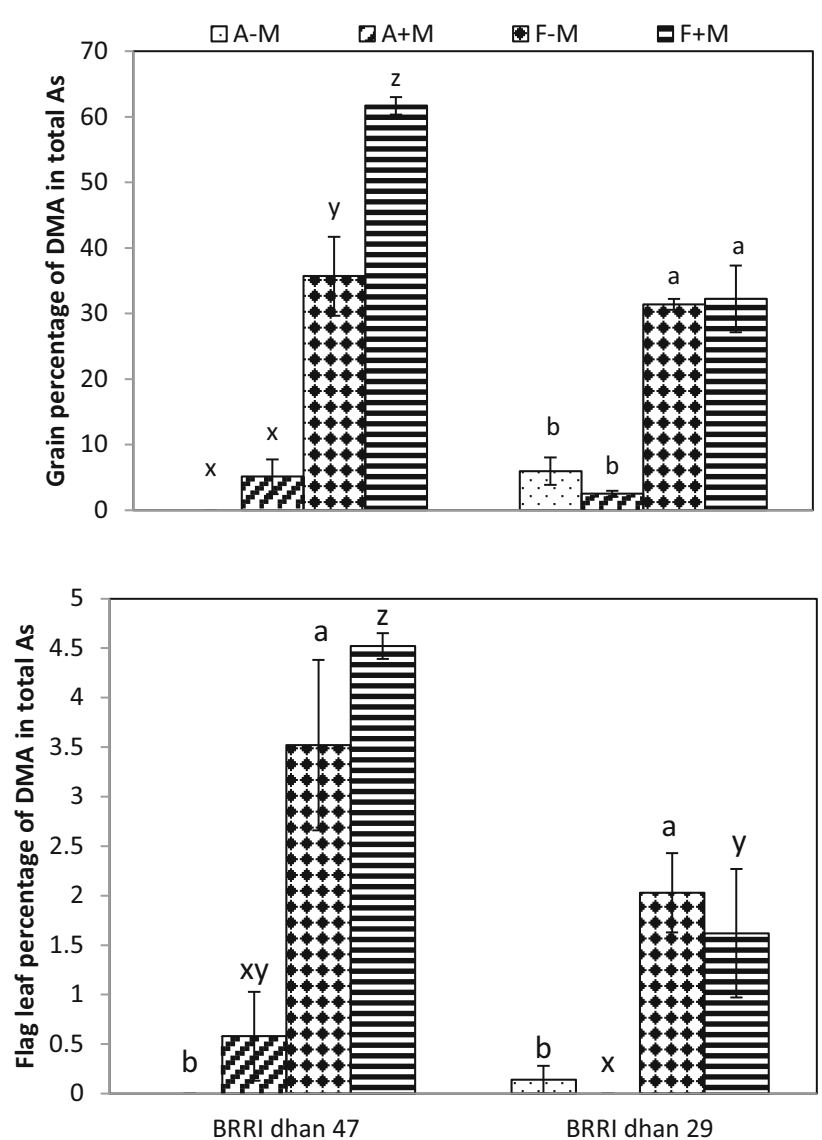

Fig. 5 Percentage of DMA in total As in grains and flag leaves of Asresistant BRRI dhan 47 and As-sensitive BRRI dhan 29 inoculated with/without $R$. irregularis grown under aerobic and flooded conditions. $\mathrm{A}-\mathrm{M}$, aerobic cultivation without inoculation; $\mathrm{A}+\mathrm{M}$, aerobic cultivation with $R$. irregularis inoculation; $\mathrm{F}-\mathrm{M}$, flooding without inoculation; $\mathrm{F}+\mathrm{M}$, flooding with $R$. irregularis inoculation. The interaction between rice varieties and water management showed significant effects on the percentage of DMA in grain and flag leaf $(P<0.05)$. The interaction between $R$. irregularis inoculation and water management also showed a significant effect on the percentage of DMA in grains $(P<0.05)$. For grain, different lower case letters ("a, b" or " $\mathrm{z}, \mathrm{y}$, $\mathrm{x}$ ") indicate significant differences $(P<0.05)$ between treatments under the same water management by Duncan's multiple range test. For flag leaf, different lower case letters (" $\mathrm{a}, \mathrm{b}$ " or " $\mathrm{z}, \mathrm{y}, \mathrm{x}$ ") indicate significant differences $(P<0.05)$ between treatments under the same inoculation treatment by Duncan's multiple range test

total As uptake increased gradually from flag leaf to rice, except for uninoculated B47 plants under aerobic conditions. A possible explanation for this observation could be that DMA is highly mobile during xylem and phloem transport in rice plants (Carey et al. 2011). DMA is preferentially accumulated in the rice grain while iAs (mostly As(III)) is mainly accumulated in the vegetative tissues (Zhao et al. 2013), and rice roots contain much less DMA than the shoots (Jia et al. 2012). However, DMA was not detected in all root samples of the two rice varieties studied here, and only small amounts of DMA were detected in the shoots of mycorrhizal plants. Thus, the methylated As in roots may have been too low to be detectable in the present study.
Apart from As speciation and concentration in rice grains, another important characteristic of rice varieties deserving attention is the grain yield. As mentioned above, As concentration in the grain of the B47 variety is significantly lower than that of B29, whereas grain yield showed no significant difference between these two rice varieties. Moreover, the grain weight of B47 was not affected by $R$. irregularis inoculation, and water management also had no influence on the grain weight of mycorrhizal B47. Thus, the rice genotype B47, which has relatively low grain As and iAs concentrations and shows no reduction in grain yield when inoculated by $R$. irregularis, is potentially an ideal candidate to be widely cultivated in As-impacted soils.

\section{Conclusion}

In conclusion, rice variety, water management, and mycorrhizal status all have profound effects on As accumulation and/or speciation in rice grains. The mycorrhizal association generally increased the proportion of DMA, and aerobic cultivation decreased As accumulation, in grains of the As-resistant B47 rice genotype. Therefore, aerobic water management along with AMF inoculation and use of the As-resistant B47 variety are potentially appropriate options that could be adopted to minimize As contamination in rice grains and thus reduce human risks from As exposure in the rice diet. Further research is necessary to reveal the underlying mechanisms of reduced As accumulation as well as As transformation in Asresistant rice varieties, which would provide important information for rice breeding.

Acknowledgments We thank Prof. M. Tofazzal Islam from Bangabandhu Sheikh Mujibur Rahman Agricultural University for kindly supplying the seeds of BRRI dhan 47 and BRRI dhan 29 for the investigation. This study was financially supported by the National Natural Science Foundation of China $(41101246,41471219)$ and the International Foundation for Science, Stockholm, Sweden, through a grant to Xin Zhang (NO. C/4973-1).

\section{References}

Abedin MJ, Feldmann J, Meharg AA (2002) Uptake kinetics of arsenic species in rice plants. Plant Physiol 128:1120-8. doi:10.1104/pp. 010733

Arao T, Kawasaki A, Baba K, Mori S, Matsumoto S (2009) Effects of water management on cadmium and arsenic accumulation and dimethylarsinic acid concentrations in Japanese rice. Environ Sci Technol 43:9361-7. doi:10.1021/es9022738

Burleigh SH, Cavagnaro T, Jakobsen I (2002) Functional diversity of arbuscular mycorrhizas extends to the expression of plant genes involved in P nutrition. J Exp Bot 53:1593-601. doi:10.1093/jxb/ erf013

Caporale AG, Sarkar D, Datta R, Punamiya P, Violante A (2014) Effect of arbuscular mycorrhizal fungi (Glomus spp.) on growth and arsenic 
uptake of vetiver grass (Chrysopogon zizanioides L.) from contaminated soil and water systems. J Soil Sci Plant Nut 14:955-72

Carey AM, Norton GJ, Deacon C et al (2011) Phloem transport of arsenic species from flag leaf to grain during grain filling. New Phytol 192: 87-98. doi:10.1111/j.1469-8137.2011.03789.x

Chan WF, Li WC, Wong MH (2015) Uptake kinetics of arsenic in upland rice cultivar Zhonghan 221 inoculated with arbuscular mycorrhizal fungi. Int J Phytorem 17:1073-80. doi:10.1080/15226514.2015. 1021952

Chen B, Xiao X, Zhu Y-G, Smith FA, Xie ZM, Smith SE (2007) The arbuscular mycorrhizal fungus Glomus mosseae gives contradictory effects on phosphorus and arsenic acquisition by Medicago sativa Linn. Sci Total Environ 379:226-34. doi:10.1016/j.scitotenv.2006. 07.038

Christophersen HM, Smith FA, Smith SE (2012) Unraveling the influence of arbuscular mycorrhizal colonization on arsenic tolerance in Medicago: Glomus mosseae is more effective than $G$. intraradices, associated with lower expression of root epidermal Pi transporter genes. Front Physiol 3:91. doi:10.3389/fphys.2012.00091

Cullen WR, Reimer KJ (1989) Arsenic speciation in the environment. Chem Rev 89:713-64. doi:10.1021/cr00094a002

Dong Y, Zhu YG, Smith FA, Wang YS, Chen BD (2008) Arbuscular mycorrhiza enhanced arsenic resistance of both white clover (Trifolium repens L.) and ryegrass (Lolium perenne L.) plants in an arsenic-contaminated soil. Environ Pollut 15:174-81. doi:10. 1016/j.envpol.2007.10.023

Fitz WJ, Wenzel WW (2002) Arsenic transformations in the soilrhizosphere-plant system: fundamentals and potential application to phytoremediation. J Biotechnol 99:259-78. doi:10.1016/s01681656(02)00218-3

Giovannetti M, Mosse B (1980) Evaluation of techniques for measuring vesicular arbuscular mycorrhizal infection in roots. New Phytol 84: 489-500. doi:10.1111/j.1469-8137.1980.tb04556.x

Gonzalez-Chavez C, Harris PJ, Dodd J, Meharg AA (2002) Arbuscular mycorrhizal fungi confer enhanced arsenate resistance on Holcus lanatus. New Phytol 15:163-71. doi:10.1046/j.1469-8137.2002. 00430.x

He XH, Lilleskov E (2014) Arsenic uptake and phytoremediation potential by arbuscular mycorrhizal fungi. In: Zakaria MS, Lynette KA, Ajit V (eds) Mycorrhizal fungi: use in sustainable agriculture and land restoration, 1st edn. Springer-Verlag, Berlin Heidelberg, pp 259-275

Jia Y, Huang H, Sun G-X, Zhao F-J, Zhu Y-G (2012) Pathways and relative contributions to arsenic volatilization from rice plants and paddy soil. Environ Sci Technol 46:8090-6. doi:10.1021/es300499a

Li RY, Ago Y, Liu WJ, Mitani N, Feldmann J, McGrath SP, Ma JF, Zhao FJ (2009a) The rice aquaporin Lsi1 mediates uptake of methylated arsenic species. Plant Physiol 150:2071-80. doi:10.1104/pp. 109. 140350

Li RY, Stroud JL, Ma JF, McGrath SP, Zhao FJ (2009b) Mitigation of arsenic accumulation in rice with water management and silicon fertilization. Environ Sci Technol 43:3778-83. doi:10.1021/ es803643y

Li H, Ye ZH, Chan WF, Chen XW, Wu FY, Wu SC, Wong MH (2011) Can arbuscular mycorrhizal fungi improve grain yield, As uptake and tolerance of rice grown under aerobic conditions? Environ Pollut 159:2537-45. doi:10.1016/j.envpol.2011.06.017

Li H, Man YB, Ye ZH, Wu C, Wu SC, Wong MH (2013) Do arbuscular mycorrhizal fungi affect arsenic accumulation and speciation in rice with different radial oxygen loss? J Hazard Mater 262:1098-104. doi:10.1016/j.jhazmat.2012.05.044

Liao XY, Chen TB, Xie H, Liu YR (2005) Soil As contamination and its risk assessment in areas near the industrial districts of Chenzhou City, Southern China. Environ Int 31:791-8. doi:10.1016/j.envint. 2005.05.030
Liu Y, Zhu YG, Chen BD, Christie P, Li XL (2005) Yield and arsenate uptake of arbuscular mycorrhizal tomato colonized by Glomus mosseae BEG167 in As spiked soil under glasshouse conditions. Environ Int 31:867-73. doi:10.1016/j.envint.2005.05.041

Lomax C, Liu WJ, Wu L, Xue K, Xiong J, Zhou J, McGrath SP, Meharg AA, Miller AJ, Zhao FJ (2012) Methylated arsenic species in plants originate from soil microorganisms. New Phytol 193:665-72. doi: 10.1111/j.1469-8137.2011.03956.x

Meharg AA (2004) Arsenic in rice- understanding a new disaster for South-East Asia. Trends Plant Sci 9:415-7. doi:10.1016/j.tplants. 2004.07.002

Meharg AA, Williams PN, Adomako E et al (2009) Geographical variation in total and inorganic arsenic content of polished (white) rice. Environ Sci Technol 43:1612-7. doi:10.1021/es802612a

Norton GJ, Islam MR, Deacon CM, Zhao FJ, Stroud JL, McGrath SP, Islam S, Jahiruddin M, Feldmann J, Price AH, Meharg AA (2009) Identification of low inorganic and total grain arsenic rice cultivars from Bangladesh. Environ Sci Technol 43:6070-5. doi:10.1021/ es $901121 \mathrm{j}$

Olsen SR, Cole CV, Watanabe FS, Dean LA (1954) Estimation of available phosphorus in soils by extraction with sodium bicarbonate. USDA Circular: No. 939:1-19. http://krishikosh.egranth.ac.in/ handle/1/2041713

Orlowska E, Godzik B, Turnau K (2012) Effect of different arbuscular mycorrhizal fungal isolates on growth and arsenic accumulation in Plantago lanceolata L. Environ Pollut 168:121-30. doi:10.1016/j. envpol.2012.04.026

Pearson JN, Jakobsen I (1993) The relative contribution of hyphae and roots to phosphorous uptake by arbuscular mycorrhiza plants, measured by dual labeling with P-32 and P-33. New Phytol 124:489-94. doi:10.1111/j.1469-8137.1993.tb03840.x

Phillips JM, Hayman DS (1970) Improved procedures for clearing roots and staining parasitic and vesicular-arbuscular mycorrhizal fungi for rapid assessment of infection. Trans Brit Mycol Soc 55:158-61

Rahman MM, Rahman MA, Maki T, Hasegawa H (2012) Phytotoxicity of arsenate and salinity on early seedling growth of rice (Oryza sativa $\mathrm{L}$.): a threat to sustainable rice cultivation in South and South-East Asia. B Environ Contam Tox 88:695-702. doi:10. 1007/s00128-012-0580-4

Schüßler A,Walker C (2010) The glomeromycota: a species list with new families and new genera 1-58. Libraries at The Royal Botanic Garden Edinburgh, The Royal Botanic Garden Kew, Botanische Staatssammlung Munich, and Oregon State University. Available at: www.amf-phylogeny.com

Sinha B, Bhattacharyya K (2015) Arsenic toxicity in rice with special reference to speciation in Indian grain and its implication on human health. J Sci Food Agric 95:1435-44. doi:10.1002/jsfa.6839

Smith SE, Read DJ (2008) Mycorrhizal symbiosis. Academic, London, UK

Smith SE, Smith FA, Jakobsen I (2004) Functional diversity in arbuscular mycorrhizal (AM) symbioses: the contribution of the mycorrhizal P uptake pathway is not correlated with mycorrhizal responses in growth or total P uptake. New Phytol 162:511-24. doi:10.1111/j. 1469-8137.2004.01039.x

Smith SE, Christophersen HM, Pope S, Smith FA (2010) Arsenic uptake and toxicity in plants: integrating mycorrhizal influences. Plant Soil 327:1-21. doi:10.1007/s11104-009-0089-8

Somenahally AC, Hollister EB, Loeppert RH, Yan WG, Gentry TJ (2011a) Microbial communities in rice rhizosphere altered by intermittent and continuous flooding in fields with long-term arsenic application. Soil Biol Biochem 43:1220-8. doi:10.1016/j.soilbio. 2011.02.011

Somenahally AC, Hollister EB, Yan WG, Gentry TJ, Loeppert RH (2011b) Water management impacts on arsenic speciation and iron-reducing bacteria in contrasting rice-rhizosphere compartments. Environ Sci Technol 45:8328-35. doi:10.1021/es2012403 
Spagnoletti F, Lavado RS (2015) The arbuscular mycorrhiza Rhizophagus intraradices reduces the negative effects of arsenic on soybean plants. Agronomy 5:188-99. doi:10.3390/ agronomy5020188

Stone R (2008) Food safety - arsenic and paddy rice: a neglected cancer risk? Science 321:184-5. doi:10.1126/science.321.5886.184

Syu CH, Huang CC, Jiang PY, Lee CH, Lee DY (2015) Arsenic accumulation and speciation in rice grains influenced by arsenic phytotoxicity and rice genotypes grown in arsenic-elevated paddy soils. $\mathrm{J}$ Hazard Mater 286:179-86. doi:10.1016/j.jhazmat.2014.12.052

Talukder ASMHM, Meisner CA, Sarkar MAR, Islam MS, Sayre KD, Duxbury JM, Lauren JG (2012) Effect of water management, arsenic and phosphorus levels on rice in a high-arsenic soil-water system: II. Arsenic uptake. Ecotox Environ Safe 80:145-51. doi:10. 1016/j.ecoenv.2012.02.020

Ultra VU, Tanaka S, Sakurai K, Iwasaki K (2007) Effects of arbuscular mycorrhiza and phosphorus application on arsenic toxicity in sunflower (Helianthus annuus L.) and on the transformation of arsenic in the rhizosphere. Plant Soil 29:29-41. doi:10.1007/s11104-0069087-2

Williams PN, Price AH, Raab A, Hossain SA, Feldmann J, Meharg AA (2005) Variation in arsenic speciation and concentration in paddy rice related to dietary exposure. Environ Sci Technol 39:5531-40. doi:10.1021/es0502324

Williams PN, Villada A, Deacon C, Raab A, Figuerola J, Green AJ, Feldmann J, Meharg AA (2007) Greatly enhanced arsenic shoot assimilation in rice leads to elevated grain levels compared to wheat and barley. Environ Sci Technol 41:6854-9. doi:10.1021/es070627i

Williams PN, Lei M, Sun G, Huang Q, Lu Y, Deacon C, Meharg AA, Zhu YG (2009) Occurrence and partitioning of cadmium, arsenic and lead in mine impacted paddy rice: Hunan, China. Environ Sci Technol 43:637-42. doi:10.1021/es802412r
Wu C, Ye Z, Shu W, Zhu Y, Wong M (2011) Arsenic accumulation and speciation in rice are affected by root aeration and variation of genotypes. J Exp Bot 62:2889-98. doi:10.1093/jxb/erq462

Xia YS, Chen BD, Christie P, Smith FA, Wang YS, Li XL (2007) Arsenic uptake by arbuscular mycorrhizal maize (Zea mays L.) grown in an arsenic-contaminated soil with added phosphorus. J Environ Sci (China) 1:1245-51. doi:10.1016/S1001-0742(07)60203-4

Xu XY, McGrath SP, Meharg AA, Zhao FJ (2008) Growing rice aerobically markedly decreases arsenic accumulation. Environ Sci Technol 42:5574-9. doi:10.1021/es800324u

Zavala YJ, Gerads R, Gürleyük H, Duxbury JM (2008) Arsenic in rice. II. Arsenic speciation in USA grain and implications for human health. Environ Sci Technol 42:3861-6. doi:10.1021/es702748q

Zhang X, Ren BH, Wu SL, Sun YQ, Lin G, Chen BD (2015) Arbuscular mycorrhizal symbiosis influences arsenic accumulation and speciation in Medicago truncatula L. in arsenic-contaminated soil. Chemosphere 119:224-30. doi:10.1016/j.chemosphere.2014.06. 042

Zhao FJ, Zhu YG, Meharg AA (2013) Methylated arsenic species in rice: geographical variation, origin, and uptake mechanisms. Environ Sci Technol 47:3957-66. doi:10.1021/es304295n

Zheng MZ, Cai C, Hu Y, Sun GX, Williams PN, Cui HJ, Li G, Zhao FJ, Zhu YG (2011) Spatial distribution of arsenic and temporal variation of its concentration in rice. New Phytol 189:200-9. doi:10.1111/j. 1469-8137.2010.03456.x

Zhu YG, Williams PN, Meharg AA (2008a) High percentage inorganic arsenic content of mining impacted and nonimpacted Chinese rice. Environ Sci Technol 42:5008-13. doi:10.1021/es8001103

Zhu YG, Williams PN, Meharg AA (2008b) Exposure to inorganic arsenic from rice: a global health issue? Environ Pollut 154:169-71. doi: 10.1016/j.envpol.2008.03.015 